\title{
Is Europe an Exceptional Case?
}

\author{
Grace Davie
}

A number of factors must be taken into account if we are to understand the place of religion in twenty-first-century Europe. ${ }^{1}$ These include the legacies of the past, more particularly the role of the historic churches in shaping European culture; an awareness that these churches still have a place at particular moments in the lives of modern Europeans, even though they are no longer able to discipline the beliefs and behavior of the great majority of the population; an observable change in the churchgoing constituencies of the continent, which operate increasingly on a model of choice, rather than a model of obligation or duty; and the arrival in Europe of groups of people from many different parts of the world, notably the global South, with very different religious aspirations from those seen in the host societies.

Each of these factors will be taken in turn in order to answer the question set out in the title: is Europe an exceptional case in terms of its patterns of religious life? The answer leads in turn to more questions. If we conclude that Europe is indeed "exceptional," why is this so? Or, conversely, why not? And what can we say about the future? Will Europe continue within the trajectory set by its past or will it become more like the patterns found elsewhere? Or-it must be asked-will the rest of the world become more like Europe?

1 Overviews of the place of religion in European societies can be found in Gerhard Robbers, ed., State and Church in the European Union (Baden-Baden: Nomos Verlagsgesellschaft, 1996); René Rémond, Religion and Society in Modern Europe (Oxford: Oxford University Press, 1999); Andrew M. Greeley, Religion in Europe at the End of the Second Millennium: A Sociological Profile (London: Transaction, 2003); John Madeley and Zsolt Enyedi, eds., Church and State in Contemporary Europe: The Chimera of Neutrality (London: Frank Cass, 2003); Hugh McLeod and Werner Ustorf, eds., The Decline of Christendom in Western Europe (Cambridge: Cambridge University Press, 2003); and in the publications emerging from the European Values Study, listed on the frequently updated EVS website <www.europeanvalues.nl/ index $2 / \mathrm{htm}>$. Alongside these overviews, there is a rapidly growing literature on the presence of Islam in Europe; see Jorgen Nielsen, Muslims in Western Europe (Edinburgh: University of Edinburgh Press, 2004) for a useful summary of this material.

Grace Davie has a personal Chair in the Sociology of Religion at the University of Exeter, where she is also the Director of the University's Centre for European Studies. She is the author of Religion in Britain since 1945 (1994), Religion in Modern Europe: A Memory Mutates (2000), and Europe: The Exceptional Case (2002). The Sociology of Religion: A Critical Agenda will appear in 2007. 


\section{Cultural Heritage}

Two points are important in relation to the role of the historic churches in shaping European culture; the Christian tradition is indeed a crucial element in the evolution of Europe, but it is by no means the only one. O'Connell identifies three formative factors or themes in the creation and re-creation of the unity that we call Europe: Judeo-Christian monotheism, Greek rationalism, and Roman organization. ${ }^{2}$ These factors shift and evolve over time, but their combinations can be seen in forming and reforming a way of life that we have come to recognize as European. The religious strand within such combinations is self-evident.

One example will suffice: the Christian tradition has had an irreversible effect on the shaping of time and space in this part of the world. Both week and year, for instance, follow the Christian cycle, even if the major festivals are beginning to lose their resonance for large sections of the population. Or to put the same point in a different way, we have had heated debates in parts of Europe about whether or not to shop on Sundays. We do not, for the most part, consider Friday an issue in this respect-though this may change. The same is true of space. Wherever you look in Europe, there is a predominance of Christian churches, some of which retain huge symbolic value. This is not to deny that in some parts of Europe (notably the larger cities) the skyline is becoming an indicator of growing religious diversity. Europe is changing, but the legacies of the past remain deeply embedded in both the physical and cultural environment.

\section{Vicarious Religion}

Physical and cultural presence is one thing; a "hands-on" role in the everyday lives of European people quite another. Commentators of all kinds agree that the latter is no longer a realistic aspiration for the historic churches of Europe. That does not mean, however, that the churches have entirely lost their significance as markers of religious identity. In my own work, I have explored this continuing ambiguity through the concept of "vicarious religion." 3

By vicarious, I mean the notion of religion performed by an active minority but on behalf of a much larger number, who (implicitly at least) not only understand, but, quite clearly, approve of what the minority is doing. The first half of the definition is relatively straightforward and reflects the everyday meaning of the term - that is, to do something on behalf of someone else (hence the word "vicar"). The second half is more controversial

\footnotetext{
2 James O'Connell, The Making of Modern Europe: Strengths, Constraints and Resolutions, University of Bradford Peace Research Report no. 26 (Bradford: University of Bradford, 1991).

3 Grace Davie, Religion in Modern Europe: A Memory Mutates (Oxford: Oxford University Press, 2000).
} 
and is best explored by means of examples. Religion, it seems, can operate vicariously in a wide variety of ways: churches and church leaders perform ritual on behalf of others; church leaders and churchgoers believe on behalf of others; church leaders and churchgoers embody moral codes on behalf of others; churches, finally, can offer space for the vicarious debate of unresolved issues in modern societies. Each of these propositions will be taken in turn in order to demonstrate the fruitfulness of looking at European religion from this point of view.

The least controversial of the above list concerns the role of both churches and church leaders in conducting ritual on behalf of a wide variety of individuals and communities at critical points in their lives. The most obvious examples can be found in the continuing requests, even in a moderately secular society, for some sort of religious ritual at the time of a birth, a marriage, and, most of all, a death. In many parts of Europe, though not in all, the demand for the first two of these diminished sharply in the later decades of the twentieth century. The same is not true with respect to churches' services at the time of a death. It is at this point, if no other, that most Europeans come into direct contact with their churches and would be deeply offended if their requests for a funeral were met with a rejection. A refusal to offer either a funeral liturgy or appropriate pastoral care would violate deeply held assumptions.

Exactly the same point can be made the other way round. It is perfectly possible to have a secular ceremony at the time of a death; de facto, however, relatively few people do this. Much more common is what might be termed a "mixed economy" funeral—that is, a liturgy in which the religious professional is present and the Christian structure maintained but filled with a variety of extraneous elements, including secular music or readings and, with increasing frequency, a eulogy rather than a homily. Princess Diana's funeral in September 1997 offers an excellent example. Churches, moreover, maintain vicariously the rituals from which a larger population can draw when the occasion demands it, and whilst that population anticipates a certain freedom in ritual expression, they also expect the institutional structures to be kept firmly in place.

But churches and church leaders do more than conduct ritual: they also believe on behalf of others. And the more senior or visible the role of the church leader, the more important it becomes that this is done properly. English bishops, to give but one example, are rebuked (not least by the tabloid press) if they doubt in public; it is, after all, their "job" to believe. The most celebrated, and not entirely justified, case of a "doubting bishop" in the Church of England was that of David Jenkins, Bishop of Durham from 1984 to $1994 .{ }^{4}$ To a large extent the controversy turned on a frequently

4 Shortly after David Jenkins' consecration in York Minster, the building was struck by lightning, an event that was seen by some as a sign of divine displeasure. This episode was given extensive press coverage at the time (July 1984). See also David Jenkins' own account in The Calling of a Cuckoo (London: Continuum, 2002). 
misquoted statement concerning the Resurrection. The phrase "not just a conjuring trick with bones" quickly turned into the opposite, for which the Bishop was widely pilloried. The cultural expectation, in other words, is that bishops believe. When they doubt, something quite clearly has gone amiss.

\section{Could it be that churches offer space} for debate regarding particular, and often controversial, topics that are difficult to address elsewhere in society?
Similar pressures emerge with respect to behavioral codes: religious professionals (both local and national) are expected to uphold certain standards of behavior-not least, more rather than less traditional representations of family life-and incur criticism when they fail, from outside churches as well as within. It is almost as if people who are not themselves participants in church life want the church's representatives to embody a certain social and moral order, thereby maintaining a way of living that has long since ceased to be the norm in the population as a whole. Failure leads to accusations of hypocrisy but also to expressions of disappointment (interestingly, royal divorces provoke a similar reaction). Such expectations become at times unreasonable, particularly in relation to the partners and children of religious personnel; it is hardly surprising that clergy families come under strain. The pressures on the Catholic priest are somewhat different, given the requirement of celibacy, but in their own way they are equally demanding.

A final possibility with respect to vicariousness develops this point further, and more provocatively. Could it be that churches offer space for debate regarding particular, and often controversial, topics that are difficult to address elsewhere in society? The current debate about homosexuality in the Church of England offers a possible example, an interpretation encouraged by the intense media attention directed at this issue-and not only in Britain. Is this simply an internal debate about senior clergy appointments in which different lobbies within the church are exerting pressure? Or is this one way in which society as a whole comes to terms with profound shifts in the moral climate? If the latter is not true, it is hard to understand why so much attention is being paid to the churches in this respect. If it is true, sociological thinking must take this factor into account. Either way, large sections of the European media are, it seems, wanting to have their cake and eat it too, pointing the spotlight at controversies within the church whilst maintaining that religious institutions must, by their very nature, be marginal to modern society.

Social scientific observers of the scene cannot afford to make a similar mistake. The public attention displayed in the examples set out above demands that we understand how religious institutions matter even to those who are not "participants" in them (in the conventional sense of the term). That, moreover, is the norm in European societies-a situation rather different from that found in the United States. Indeed, in a decade of lecturing across both Europe and the U.S., I have seldom met an audience in the former who do not immediately grasp the notion of vicariousness and its implica- 
tions for the European scene. This is much less the case in the United States, where the connections between the population and their religious organizations are very differently understood. There are exceptions, but to act vicariously is not part of American self-understanding. ${ }^{5}$

Herein, moreover, lies an important explanation for the "exceptional" nature of Europe's religion. It derives from a particular history of state-church relationships, out of which grows the notion of a state church (or its successor) as a public utility rather than a private organization. A public utility is available to the population as a whole at the point of need and is funded through the tax system. Precisely that combination remains in place in the Lutheran countries of Europe. Elsewhere both constitutional and financial arrangements have been modified (sometimes radically), but the associated mentalities are, it seems, more difficult to shift.

\section{From Obligation to Consumption}

The changing nature of churchgoing in modern Europe is important to understand, and to do so, one must clarify the constituency: here are Europe's diminishing, but still significant churchgoers - those who maintain the tradition on behalf of the people described in the previous section. And here an observable change is taking place: from a culture of obligation or duty to a culture of consumption or choice. What until somewhat recently was simply imposed (with all the negative connotations of this word), or inherited (a rather more positive spin), becomes instead a matter of personal choice: "I go to church (or to another religious organization) because I want to, maybe for a short period or maybe for longer, to fulfill a particular rather than a general need in my life and where I will continue my attachment so long as it provides what I want, but I have no obligation either to attend in the first place or to continue if I don't want to."

As such, this pattern is entirely compatible with vicariousness: "the churches need to be there in order that I may attend them if I so choose." The "chemistry," however, gradually changes, a shift that is discernible in both practice and belief, not to mention the connections between them. There is, for example, an easily documentable change in the patterns of confirmation in the Church of England. The overall number of confirmations has dropped dramatically in the post-war period, evidence once again of institutional decline. In England, though not yet in the Nordic countries, confirmation is no longer a teenage rite of passage, but a relatively rare event undertaken as a matter of personal choice by people of all ages. Indeed, there is a very marked rise in the proportion of adult confirmations among the candidates overall-up to 40 percent by the mid-1990s (by no means enough, however, to offset the fall among teenagers).

5 Grace Davie, "Vicarious Religion: A Methodological Challenge," Religion in Modern Lives, ed. Nancy Ammerman (New York: Oxford University Press, forthcoming). 
Confirmation becomes, therefore, a very significant event for those individuals who choose this option, an attitude that is bound to affect the rite itself-which now includes the space for a public declaration of faith. Confirmation becomes an opportunity to make public what has often been an entirely private activi-

Taken together, these events indicate a marked change in the nature of membership in the historic churches... ty. It is increasingly common, moreover, to baptize an adult candidate immediately before the confirmation, a gesture which is evidence in itself of the fall in infant baptism some twenty to thirty years earlier. Taken together, these events indicate a marked change in the nature of membership in the historic churches, which become, in some senses, much more like their non-established counterparts. Voluntarism

(a market) is beginning to establish itself de facto, regardless of the constitutional position of the churches. Or to continue the "chemical" analogy a little further, a whole set of new reactions are set off that in the longer term (the stress is important) may have a profound effect on the understanding of vicariousness.

The trends are considerably more visible in some parts of Europe than in others. There is, for instance, a marked parallel between the Anglicans and the Catholic Church in France in this respect: adult baptisms in the Church of England match very closely those in France-indeed, the similarity in the statistics is almost uncanny, given the very different ecclesiologies embodied in the two churches (one Catholic and one Protestant). ${ }^{6}$ But it is precisely this shift across very different denominations that encourages the notion that something profound is taking place. Lutheran nations, however-despite their reputation for being the most secular countries in Europe-still stick to a more traditional pattern as far as confirmation is concerned, though the manner in which they do this is changing. Large numbers of young people now choose the option of a confirmation camp rather than a series of weekly meetings. ${ }^{7}$ In making this choice, confirmation becomes an "experience" in addition to a rite of passage, implying a better fit with other aspects of youth culture.

The stress on experience is important in other ways as well. It can be seen in the choices that the religiously active appear to be making, at least in the British case. Here, within a constituency that is evidently reduced, two options stand out as disproportionately popular. The first is the conservative evangelical church-the success story of late twentieth-century churchgoing, both inside and outside the mainstream. These are churches that draw their members from a relatively wide geographical area and work on a congregational, rather than parish, model. Individuals are invited to opt in rather than opt out, and membership implies commitment to a set of specified beliefs and behavioral codes. For significant numbers of people, these churches offer firm boundaries, clear

6 Davie, Religion in Modern Europe, 71-2.

7 The figures for confirmation stay particularly high in Finland. 
guidance, and considerable support-effective protection from the vicissitudes of life. Interestingly, however, it is the softer charismatic forms of evangelicalism that are doing particularly well; old-fashioned Biblicism, relatively speaking, is losing its appeal.

Very different and less frequently recognized in the writing about religion in modern Britain (as indeed in Europe) is the evident popularity of cathedrals and city-center churches. Cathedrals and their equivalents deal with diverse constituencies. Working from the inside out, they are frequented by regular and irregular worshippers, pilgrims, visitors, and tourists, though the lines between these groups frequently blur. The numbers, moreover, are considerable - the more so on special occasions, both civic and religious. Hence, concerns about upkeep and facilities lead to difficult debates about finance. Looked at from the point of view of consumption, however, cathedrals are places that offer a distinctive product: traditional liturgy, top-class music, and excellence in preaching, all of which take place in a historic and often very beautiful building. A visit to a cathedral is an aesthetic experience, sought after by a wide variety of people, including those for whom membership or commitment presents difficulties. They are places where there is no obligation to opt in or to participate in communal activities beyond the service itself. In this respect, they become almost the mirror image of the evangelical churches already described. ${ }^{8}$

What then is the common feature in these very different stories? It is the experiential or "feel-good" factor, whether this be expressed in charismatic worship, in the tranquility of cathedral evensong, or in a special cathedral occasion (a candlelit carol service or a major civic event). The point is that we feel something; we experience the sacred, the set apart. The purely cerebral is less appealing. Durkheim was entirely correct in this respect: it is the taking part that matters for late modern populations and the feelings so engendered. ${ }^{9}$ If we feel nothing, we are much less likely either to take part in the first place or to continue thereafter.

\section{New Arrivals}

The final factor in this complicated mosaic is somewhat different: the growing number of incomers in almost all European societies. There have been two stages in this process. The first was closely linked to the need for labor in the expanding economies of post-war Europe-notably in Britain, France, Germany, and the Netherlands. Wherever possible, each of these countries looked to its former empire to expand its workforce: Britain to the West Indies and the Indian sub-continent, France to the

8 The attraction of cathedrals and city-center churches is closely related to the growth in pilgrimage across Europe; see Davie, Religion in Modern Europe, 156-62.

9 See in particular Emile Durkheim, The Elementary Forms of Religious Life (1912; London: Harper Collins, 1976). 
Mahgreb, Germany (with no empire) to Turkey and the former Yugoslavia, and the Netherlands to its overseas connections (Indonesia and Surinam), but also to Morocco. The second wave of immigration occurred in the 1990s and included, in addition to the places listed above, both the Nordic countries and the countries of Mediterranean Europe (Greece, Italy, Spain, and Portugal) - bearing in mind that the latter, until very recently, have been countries of emigration rather than immigration. The turnaround has been truly remarkable - the sharpest illustration of all being the transformation in the 1990s of Dublin, Ireland, from a relatively poor city to a thriving, expensive, and increasingly diverse place to live. ${ }^{10}$

Different host societies and different countries of provenance have led to a complex picture-generalization is dangerous. Some points are, however, common to most, if not all, cases. It is important to remember that those who are arriving in Europe are coming primarily for economic reasons - they are coming to work. If the first wave provided labor for expanding industrial economies, the second filled a rather different gap. As the twentieth century drew to a close, Europeans were becoming increasingly aware that there were insufficient numbers to employ in Europe to support the rising proportion of dependent people_-notably the growing number of retired. The pull factor in this case is the shifting demographic profile in Europe. A second point follows from this: all is well, or relatively well, as long as there is sufficient work for everyone in an economy able to maintain the services necessary for incoming populations. All is less well when there is a downturn in the economy (as happened in the late 70s and 80s) or when those who work to support dependent Europeans become dependent themselves. Hence the unrest in France in the autumn of 2005: a population excluded both from the economy itself, and from its concomitant benefits, expressed its frustration on the streets.

What, though, are the implications for the religious life of Europe? The short answer is that they vary from place to place depending on both host society and new arrivals. Britain and France offer an interesting comparison. In Britain immigration has been much more varied than in France, both in terms of provenance and in terms of faith communities. West Indians, for example, are Christians - and much more formed in their Christianity than their British equivalents. One result of this is the vibrant AfroCaribbean churches of Britain's larger cities - some of the most active Christian communities in the country. ${ }^{11}$ From the sub-continent, moreover, come Sikhs and Hindus as well as a sizeable number of Muslims (1.5 million). Britain is also a country where ethnicity and religion criss-cross each other in a bewildering variety of ways (only Sikhs and Jews claim ethno-religious identities). The situation in France is very different:

${ }^{10}$ In terms of its religious life, Ireland is in many respects a "Mediterranean" country. It is also very like Poland, insofar as Catholicism has become a marker of national identity.

11 There is a negative side to this story. For a variety of reasons, among them racism, Afro-Caribbeans were largely excluded from mainstream churches when they first arrived in Britain, an episode that the historic churches have come to regret bitterly. 
here immigration has been largely from the Maghreb, as a result of which France has by far the largest Muslim community in Europe (between 5 and 6 million) —an almost entirely Arab population. Rightly or wrongly, "Arab" and "Muslim" have become interchangeable terms in popular parlance in France.

Britain and France can be compared in other ways as wellan exercise that provokes some interesting questions, among them the tensions between democracy and tolerance. France, for example, is markedly more democratic than Britain on almost all institutional or constitutional measures. France is a Republic, with a secular state, two elected chambers, and no Rightly or wrongly, "Arab" and "Muslim" have become interchangeable terms in popular parlance in France. privileged church (in the sense of connections to the state). There is a correspondingly strong stress on the equality of all citizens whatever their ethnic or religious identity. Hence, France holds a strongly assimilationist policy towards incomers, with the express intention of eradicating difference-individuals who arrive in France are welcome to maintain their religious belief and practices, provided these are relegated to the private sphere. They are actively discouraged from developing any kind of group identity. Exactly the same point can be put as follows: any loyalty (religious or otherwise) that comes between the citizen and the state in France is regarded in negative terms. The result, whether intended or not, is a relative lack of tolerance, if by tolerance is meant the freedom to promote collective as well as individual expressions of religious identity - that is, those expressions that impact the public as well as the private sphere.

Britain is very different. On a strict measure of democracy, Britain fares less well than France-with no written constitution, a monarchy, a half-reformed and so far unelected House of Lords, and an established church. More positively, Britain has a more developed tradition of accommodating group identities (including religious identities) within the framework of British society, a feature that owes a good deal to the relatively greater degree of religious pluralism that has existed in Britain for centuries rather than decades. Hence a markedly different policy towards newcomers: the goal becomes the accommodation of difference rather than its eradication. Rather more provocative, however, are the conclusions that emerge if you look carefully at who, precisely, in British society is advocating religious as opposed to ethnic toleration. Very frequently it turns out to be those in society who do not depend on an electoral mandate: the royal family, significant spokespersons in the House of Lords (where other faith communities are well represented by appointment, not by election), and prominent members of the established Church. The latter, in fact, become the protectors of "faith" in general rather than the protectors of specifically English expressions of Christianity. ${ }^{12}$

12 For a more detailed presentation of this argument, including the discussion of specific examples, see Grace Davie, "Pluralism, Tolerance and Democracy: Theory and Practice in Europe," The New Religious Pluralism and Democracy, ed. Thomas Banchoff (New York: Oxford University Press, forthcoming). 
One further point is significant and reflects a shift that is taking place right across Europe. The growing presence of other faith communities in general, and of the Muslim population in particular, is challenging some deeply held European assumptions. The notion that faith is a private matter and should, therefore, be proscribed from public life-notably from the state and from the education system-is wide-

The growing presence of other faith communities in general, and of the Muslim population in particular, is challenging some deeply held

European assumptions. spread in Europe (not only in France). Conversely, many of those who are currently arriving in this part of the world have markedly different convictions, and offer-simply by their presence- a challenge to the European way of doing things. Reactions to this challenge vary from place to place, but at the very least, European societies have been obliged to re-open debates about the place of religion in public as well as private life-hence the heated controversies about the wearing of the veil in the school system and about the rights or wrongs of publishing material that one faith community in particular finds offensive. The repercussions of the now famous (or infamous) Danish cartoons are a case in point. ${ }^{13}$ The lack of comprehension on both sides of this affair, together with an unwillingness to compromise, led alarmingly fast to dangerous confrontations, both in Europe and beyond.

Such episodes raise a further point which, if developed, could become an article in its own right. That is the extent to which the secular elites of Europe use these events in order to articulate an ideological alternative to religion. The point to grasp in the space that remains in this paper is that such elites - just like their religious alter-egosvary markedly from place to place. The fact that the cartoons were first published in Denmark was not simply a coincidence; nor was the insistence on the part of the media in some countries rather than others (most notably France) that the cartoons should be repeatedly re-published in order to affirm the freedom of speech. Such attitudes have historical roots. France, for example, is the European society where the Enlightenment has been most obviously configured as a freedom from belief, an attitude which finds expression in the democratic, though not always very tolerant, institutions already described. In the United States, the Enlightenment becomes something very different: a freedom to believe. A developed treatment of this theme would reveal, however, that other European societies (much of Northern Europe, Germany, and Italy) fall somewhere between the two. Europe as ever is far from homogeneous.

\footnotetext{
13 The cartoons were first published in the autumn of 2005 and reprinted in many parts of Europe in the early months of 2006. The depictions of Mohammed were considered derogatory by many sections of the Muslim community; for most Europeans, they were simply "cartoons."
} 


\section{Concluding Remarks}

Several things are happening simultaneously in the religious life of Europe. The fact that they are occurring at the same time is partly a coincidence-each, however, encourages the other. The historic churches, despite their continuing presence, are losing their capacity to discipline the religious thinking of large sections of the population (especially the young). Simultaneously, the range of religious choice is widening all the time both inside and outside the historic churches. New forms of religion are coming into Europe from outside, largely as the result of the movement of people. Finally, at least some of the people arriving from outside are offering a significant challenge to the widely held assumptions about the place of religion in European societies.

It is equally clear that at least some aspects of exceptionality can be pursued by framing these statements in the form of questions, and by looking carefully at their implications for the religious life of Europe. For example: is Europe likely to produce a religious market like that found in the United States? The turn from obligation to consumption could be seen in this light. Conversely: is the residue of the state church sufficiently strong to resist this-maintaining thereby the notion of religion as a public utility rather than a freely chosen voluntary activity? And where in these complex equations do we place the newly arrived populations, whether Christian or not?

The answers must be tentative, but I will offer three; the last takes the form of a cautious prediction about the future of religion in Europe.

There are effectively two religious economies in Europe, which run alongside each other. The first is an incipient market, which is emerging among the churchgoing minorities of most, if not all, European societies, and in which voluntary membership is becoming the norm, de facto if not de jure. The second economy resists this tendency and continues to work on the idea of a public utility, in which membership remains ascribed rather than chosen. In this economy opting out, rather than opting in, remains the norm and is most visible at the time of a death. Interestingly, the two economies are in partial tension, but also depend upon each other-each fills the gaps exposed by the other. Exploring these tensions offers a constructive route into the complexities of European religion in the twenty-first century.

Religion will increasingly penetrate the public sphere, a tendency driven largely by the presence of Islam in different parts of Europe. Paradoxically, in many ways this is easier for the active, increasingly voluntarist, Christian minorities to understand than those who remain passively attached to their (public) historic churches. For the former, seriously held belief leads to public implications; for the latter, seriously held belief is seen as a threat rather than an opportunity.

The religious situation in Europe is and will remain distinctive (if not exceptional), given the legacies of the past. It is not, however, static. Clearly things are changing, 
and in some places very fast. Exactly how they will evolve is not easy to say, but I will conclude by making a cautious and three-fold prediction - the first part is tentative, the second more certain, and the third increasingly evident. First-I think that vicarious religion will endure at least until the mid-century, but maybe not for much longer. It follows that the actively religious in Europe will increasingly work on a market model, but the fact that their choices will include the historic churches complicates the issue (the alternatives are not as mutually exclusive as they first appear). Second-I know that the presence of Islam is a crucial factor that we ignore at our peril. Not only does it offer an additional choice, but it has become a catalyst of a much more profound change in the religious landscape of Europe. Finally, the combination of all these factors will increase rather than decrease the salience of religion in public, as well as private, debate- a tendency encouraged by the ever more obvious presence of religion in the modern world order. In this respect, the world is more likely to influence the religious life of Europe than the other way round. 